Article

\title{
Batch Studies of Phosphonate and Phosphate Adsorption on Granular Ferric Hydroxide (GFH) with Membrane Concentrate and Its Synthetic Replicas
}

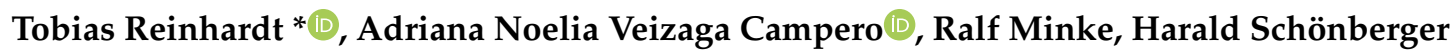 \\ and Eduard Rott
}

Institute for Sanitary Engineering, Water Quality and Solid Waste Management (ISWA), University of Stuttgart, Bandtäle 2, 70569 Stuttgart, Germany; an.veizaga@gmail.com (A.N.V.C.); ralf.minke@iswa.uni-stuttgart.de (R.M.); harald.schoenberger@iswa.uni-stuttgart.de (H.S.)

* Correspondence: tobias.reinhardt@iswa.uni-stuttgart.de; Tel.: +49-711-685-65415

Academic Editor: Ming-Chung Wu

Received: 21 October 2020; Accepted: 4 November 2020; Published: 9 November 2020

check for updates

\begin{abstract}
Phosphonates are widely used as antiscalants for softening processes in drinking water treatment. To prevent eutrophication and accumulation in the sediment, it is desirable to remove them from the membrane concentrate before they are discharged into receiving water bodies. This study describes batch experiments with synthetic solutions and real membrane concentrate, both in the presence of and absence of granular ferric hydroxide (GFH), to better understand the influence of ions on phosphonate and phosphate adsorption. To this end, experiments were conducted with six different phosphonates, using different molar Ca:phosphonate ratios. The calcium already contained in the GFH plays an essential role in the elimination process, as it can be re-dissolved, and, therefore, increase the molar Ca:phosphonate ratio. (Hydrogen-)carbonate ions had a competitive effect on the adsorption of phosphonates and phosphate, whereas the influence of sulfate and nitrate ions was negligible. Up to $\mathrm{pH} 8$, the presence of $\mathrm{Ca}^{\mathrm{II}}$ had a positive effect on adsorption, probably due to the formation of ternary complexes. At $\mathrm{pH}>8$, increased removal was observed, with either direct precipitation of Ca:phosphonate complexes or the presence of inorganic precipitates of calcium, magnesium, and phosphate serving as adsorbents for the phosphorus compounds. In addition, the presence of (hydrogen-)carbonate ions resulted in precipitation of $\mathrm{CaCO}_{3}$ and/or dolomite, which also acted as adsorbents for the phosphorus compounds.
\end{abstract}

Keywords: calcium; (hydrogen-)carbonate; DTPMP; HEDP; NTMP; precipitation

\section{Introduction}

In recent years, global phosphonate consumption has increased from 56,000 t/yr (1998) to 94,000 t/yr (2012) [1,2]. Phosphonates are complexing agents widely used as antiscalants for softening processes in drinking water treatment [3-5]. The resulting membrane concentrate is often disposed of into a receiving water body without any further treatment [6-8]. A recent study shows the effects of wastewater on the occurrence of various phosphonates in rivers [9]. A significant increase of adsorbed phosphonates in the sediment, which was due to wastewater discharge, was observed. This is of particular interest, since to date, very little is known about the long-term effects of phosphonates in surface waters. Since UV radiation can promote the degradation of phosphonates to readily available orthophosphate, they can contribute to the eutrophication of water bodies [10,11].

By complexing calcium ions [12] and adsorbing on active growth sites of crystals, phosphonates can inhibit $\mathrm{CaCO}_{3}$ precipitation [13-15]. Due to their threshold effect, they are effective even in substoichiometric concentrations [16]. It is known that phosphonates can adsorb on granular 
ferric hydroxides (GFH) $[4,17,18]$ as mono-, bi-, or tridentate complexes $[19,20]$. Calcium ions, whose precipitation is to be prevented by phosphonates, simultaneously have a positive influence on the adsorption of phosphonates on GFH due to the formation of ternary surface complexes $[19,21]$. The influence of other ions such as magnesium [17] and sulfate [4] on the adsorption on GFH has also been investigated in previous studies.

So far, however, hardly any studies have been published on the influence of a mixture of different ions usually present in membrane concentrates on the adsorption of phosphonates on GFH. Although various phosphonates with different properties are used as antiscalants, only one phosphonate, nitrilotrimethylphosphonic acid (NTMP), has been examined in these studies. Furthermore, little attention has been paid thus far to the possible impacts of potential precipitation.

In a previous study, Reinhardt et al. [18] compared the adsorption of various phosphonates on four different GFH adsorbents. They showed that phosphonates with different properties, such as molecular size and weight, or the number of phosphonate groups, display different behaviors during adsorption. The $\mathrm{pH}$ for phosphonate adsorption on GFH should be close to 6. It may be possible to reuse GFH. The authors concluded that further experiments with real wastewater must be conducted in order to investigate the competing or supporting influence of other ions.

With the aim of closing the knowledge gaps mentioned above, this study describes batch experiments with the best-performing GFH used in the previous study. In four experiments, the influence of ions present in membrane concentrate on phosphonate adsorption was investigated (mainly focusing on calcium ions). Additional batches that did not include GFH were conducted to investigate whether the observed elimination could be caused by precipitation. For a better understanding of the process, experiments were first performed with synthetic replicas, before conducting subsequent batches with real membrane concentrate. Figure 1 shows the six investigated phosphonates in this study.

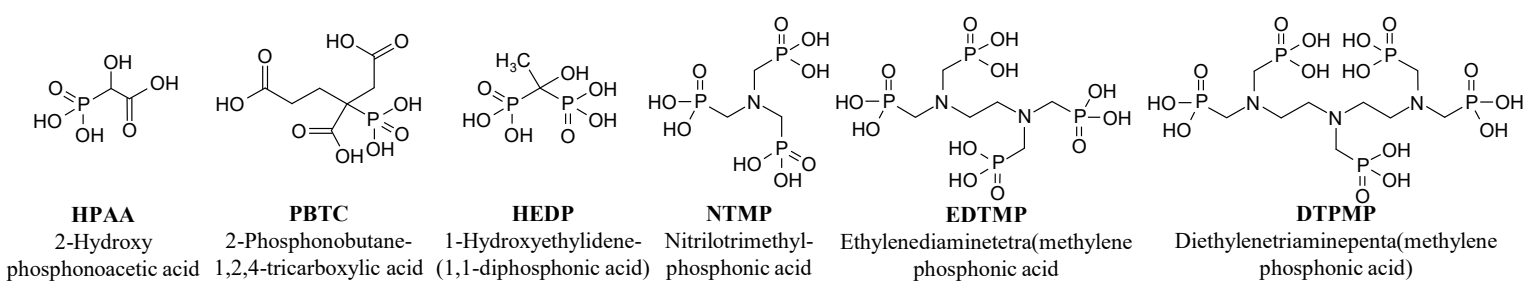

Figure 1. Chemical structures of considered phosphonates.

\section{Materials and Methods}

\subsection{Reagents and Chemicals}

All solutions were prepared with deionized water made from drinking water in the laboratory, using an ion exchanger (Seradest SD 2000, ELGA LabWater, Celle, Germany) and a downstream filter unit (Seralpur PRO $90 \mathrm{CN}$ ).

Acetic acid (AcOH) (100\%, Ph. Eur.) and $\mathrm{HCl}$ solution (32\%, AnalaR NORMAPUR) were obtained from VWR Chemicals (Fontenay-sous-Bois, France). $\mathrm{NaNO}_{3}\left(>99 \%\right.$, Ph. Eur.), $\mathrm{Na}_{2} \mathrm{SO}_{4}(\geq 99 \%$, p. a.), $\mathrm{CaCl}_{2} \cdot 2 \mathrm{H}_{2} \mathrm{O}\left(\geq 99.5 \%\right.$, p. a.), $\mathrm{MgCl}_{2} \cdot 6 \mathrm{H}_{2} \mathrm{O}$ ( $\geq 99 \%$, Ph. Eur.), $\mathrm{KH}_{2} \mathrm{PO}_{4}(\geq 99.5 \%$, p. a.), and $\mathrm{NaOH}$ ( $\geq 99 \%$, Ph. Eur.) were purchased from Merck (Darmstadt, Germany). $\mathrm{NaHCO}_{3}$ ( $\geq 99 \%$, Ph. Eur.) was purchased from Carl Roth (Karlsruhe, Germany). Ethylenedinitrilotetraacetic acid disodium salt dihydrate (EDTA-Na $\mathrm{Na}_{2}$ dihydrate, Titriplex III, 99-101\%, Ph. Eur.) was obtained from Merck (Darmstadt, Germany).

The buffers (2-(N-morpholino)ethanesulfonic acid (MES) ( $\geq 99 \%)$, 3-( $N$-morpholino) propanesulfonic acid (MOPS) ( $\geq 99.5 \%)$, 4-(2-hydroxyethyl)-piperazine-1-propanesulfonic acid (EPPS) ( $\geq 99.5 \%), \quad 3-N$-cyclohexylamino-2-hydroxypropanesulfonic acid (CAPSO) ( $\geq 99 \%)$, 
and 3-(cyclohexylamino)-1-propanesulfonic acid (CAPS) ( $\geq 98 \%$ ) were purchased from Sigma Aldrich (St. Louis, MO, USA).

HPAA was purchased from Connect Chemicals (Ratingen, Germany) as a technical solution (50\%). PBTC, as a technical solution (50\%, CUBLEN P 50), as well as EDTMP (5.3\% water of crystallization) and DTPMP (16\% water of crystallization), both as solids, were supplied by Zschimmer \& Schwarz Mohsdorf (Burgstädt, Germany). HEDP. $\mathrm{H}_{2} \mathrm{O}(\geq 95 \%)$ and NTMP $(\geq 97 \%)$ were purchased from Sigma-Aldrich (St. Louis, MO, USA).

\subsection{Adsorbent}

A previous study comparing the adsorption of phosphonates on different granular ferric hydroxides (GFH) showed that FerroSorp RW had the highest adsorption capacity of the compared adsorbents [18]. Therefore, FerroSorp RW from HeGo Biotec GmbH was used in this study. Prior to the experiments, the adsorbent was rinsed once over a sieve with distilled water until the water ran clear to remove GFH dust, and then the GFH was air-dried under a fume hood. The screen mesh width was chosen to ensure a maximum separation of 3 Mass- $\%$ of the adsorbent as ultra-fine particles during the rinsing process. The FerroSorp RW that was used had a grain size of 0.5-2.5 mm after rinsing, a point of zero charge $\left(\mathrm{pH}_{\mathrm{PZC}}\right)$ of 8.6 , and a specific surface area of $210 \mathrm{~m}^{2} / \mathrm{g}$. According to the manufacturer, it has a calcium content of $\geq 12-19 \%$ (mainly $\mathrm{CaCO}_{3}$ ).

\subsection{Membrane Concentrate and Its Synthetic Replicas}

The membrane concentrate was taken from a low pressure reverse osmosis (LPRO) plant at a public waterworks. It was a clear $(0.11 \mathrm{NTU})$, colorless solution with a low organic load (16.1 mg/L COD). It was characterized by concentrations of $613 \mathrm{mg} / \mathrm{L} \mathrm{Ca}^{2+}$ and $75 \mathrm{mg} / \mathrm{L} \mathrm{Mg}^{2+}$ and the associated exceptionally high level of water hardness, combined with a very high buffer capacity (alkalinity $=$ $26.6 \mathrm{mmol} / \mathrm{L}$ ). The $\mathrm{pH}$ value of the sample was approx. 7.9 , the electrical conductivity $3.14 \mathrm{mS} / \mathrm{cm}$, the $\mathrm{Cl}^{-}$concentration $229 \mathrm{mg} / \mathrm{L}$, the $\mathrm{SO}_{4}{ }^{2-}$ concentration $474 \mathrm{mg} / \mathrm{L}$, and the $\mathrm{NO}_{3}{ }^{-}$concentration $67.7 \mathrm{mg} / \mathrm{L}$. The total $\mathrm{P}$ of the sample was $1.27 \mathrm{mg} / \mathrm{L}$, and the dissolved $\mathrm{P}$ fraction (total P fraction of the membrane-filtered sample) was $1.27 \mathrm{mg} / \mathrm{L}$ as well. Thus, the particulate $\mathrm{P}$ fraction was negligible. The $\mathrm{o}-\mathrm{PO}_{4}{ }^{3-}$-P fraction was $0.53 \mathrm{mg} / \mathrm{L}$, and consequently the organic $\mathrm{P}$ fraction was $0.74 \mathrm{mg} / \mathrm{L} \mathrm{P}$. The antiscalant (DTPMP) was added to the raw water in the waterworks at a dosage of $0.6 \mathrm{mg} / \mathrm{L}$. With an average nanofiltration yield of $80 \%$, the added antiscalant was concentrated by a factor of five. Thus, the membrane concentrate contains approx. $3 \mathrm{mg} / \mathrm{L}$ DTPMP, which corresponds to $0.81 \mathrm{mg} / \mathrm{L}$ DTPMP-P. Therefore, it is assumed that the organic P fraction consisted almost exclusively of DTPMP. The experiments were started on the day of sampling.

Synthetic replicas of the membrane concentrate were prepared to investigate the influence of different ions. The concentrations of the compounds in the synthetic replicas matched the concentration of the individual compounds in the membrane concentrate. The composition of the synthetic solutions used is shown under the headings A-N in Table 1, the composition of the membrane concentrate under the heading MC. Preliminary experiments (not described here in detail) showed that the corresponding counterions $\mathrm{Na}^{+}$and $\mathrm{Cl}^{-}$did not have any effect on the adsorption. Since synthetic wastewater lacks the buffering capacity of real wastewater, the addition of an organic buffer $(0.01 \mathrm{M})$ was necessary to keep the $\mathrm{pH}$ stable during the adsorption experiments. The influence of the buffers on phosphorus analysis is negligible [22]. 
Table 1. Composition of the solutions. A-N: synthetic replicas, MC: membrane concentrate.

\begin{tabular}{ccccccccccccccccc}
\hline & \multicolumn{10}{c}{ Solutions } & \multicolumn{10}{c}{} \\
\hline Compound & Unit & A & B & C & D & E & F & G & H & I & J & K & L & M & N & MC \\
\hline DTPMP-P & $\mathrm{mg} / \mathrm{L}$ & 0.74 & - & 0.74 & 0.74 & 0.74 & 0.74 & 0.74 & 0.74 & 0.74 & 0.74 & 0.74 & 0.74 & 0.74 & 0.74 & 0.74 \\
$\mathrm{PO}_{4}-\mathrm{P}$ & $\mathrm{mg} / \mathrm{L}$ & - & 0.53 & 0.53 & 0.53 & 0.53 & 0.53 & 0.53 & 0.53 & 0.53 & 0.53 & 0.53 & 0.53 & 0.53 & 0.53 & 0.53 \\
$\mathrm{NO}_{3}{ }^{-}$ & $\mathrm{mg} / \mathrm{L}$ & - & - & - & 67.7 & - & - & - & 67.7 & - & - & - & - & - & 67.7 & 67.7 \\
$\mathrm{SO}_{4}^{2-}$ & $\mathrm{mg} / \mathrm{L}$ & - & - & - & - & 474 & - & 474 & 474 & - & - & - & 474 & 474 & 474 & 474 \\
$\mathrm{HCO}_{3}{ }^{-}$ & $\mathrm{mg} / \mathrm{L}$ & - & - & - & - & - & 1620 & 1620 & 1620 & - & - & - & - & 1620 & 1620 & 1620 \\
$\mathrm{Ca}^{2+}$ & $\mathrm{mg} / \mathrm{L}$ & - & - & - & - & - & - & - & - & 613 & - & 613 & 613 & 613 & 613 & 613 \\
$\mathrm{Mg}^{2+}$ & $\mathrm{mg} / \mathrm{L}$ & - & - & - & - & - & - & - & - & - & 75.0 & 75.0 & 75.0 & 75.0 & 75.0 & 75.0 \\
\hline
\end{tabular}

\subsection{Experimental Procedure}

Experiments were conducted both with synthetic solutions and with real wastewater. P-containing solutions with different $\mathrm{pH}$ values, adjusted with $\mathrm{HCl}$ or $\mathrm{NaOH}$, were prepared. For each investigated $\mathrm{pH}$, a buffer was added (target $\mathrm{pH}$ value $\left(\mathrm{pH}_{\text {target }}\right)$ with buffer concentration in brackets): $\mathrm{pH} 5(0.01 \mathrm{M}$ AcOH), pH 6 (0.01 M MES), pH 7 (0.01 M MOPS), pH 8 (0.01 M EPPS), pH 9 (0.01 M CAPSO), pH 10 (0.01 M CAPS), and pH $12(0.01 \mathrm{M} \mathrm{NaOH})$.

After the required amount of adsorbent was weighed into a $50 \mathrm{~mL}$ centrifuge tube, the tube was filled with the buffered P-containing solution up to the $50 \mathrm{~mL}$ mark, immediately capped, and then clamped in the overhead rotator (LLG-uniROTATOR 2) running at $20 \mathrm{rpm}$. The centrifuge tube was removed after a contact time of seven days, and approx. $20 \mathrm{~mL}$ of the supernatant was filtered into an empty glass bottle using a two-part disposable syringe (Norm-Ject, $20 \mathrm{~mL}$, Henke Sass Wolf, Tuttlingen, Germany) with an attachable $0.45 \mu$ m nylon filter (Sartorius Stedim Biotech GmbH, Göttingen, Germany). A previous study showed that the relatively long contact time of seven days was necessary to achieve equilibrium [18]. This contact time could have been reduced by grinding the adsorbent or by a higher rotation speed, which would have led to more abrasion of the adsorbent. Since it is known that the particle radius of the adsorbent has an influence on the adsorption behavior [23], the adsorbent should be left as undamaged as possible to allow a better comparison with future column experiments. In a possible future engineering application with filter columns, however, significantly shorter contact times can be achieved, since no equilibrium is necessary in this case. Total $\mathrm{P}$ (dissolved), orthophosphate- $\mathrm{P}$, and $\mathrm{pH}\left(\mathrm{pH}_{\text {end }}\right)$ were determined from the filtrate. As it is possible for $\mathrm{pH}_{\text {end }}$ to deviate from $\mathrm{pH}_{\text {target }}$, the figures show $\mathrm{pH}_{\text {end }}$, which is considered to be more relevant.

Dissolved phosphonates are part of the dissolved unreactive phosphorus (DUP) fraction in wastewater, which corresponds to the difference between dissolved P (total P of membrane-filtered sample) and orthophosphate-P [24]. Therefore, organic P concentrations in $\mathrm{mg} / \mathrm{L}$ were calculated in accordance with Equation (1).

$$
c(\text { DUP })=c(\text { dissolved } \mathrm{P})-\mathrm{c}\left(\mathrm{o}-\mathrm{PO}_{4}-\mathrm{P}\right)
$$

Experiment 1 served to investigate the influence of $\mathrm{Ca}^{\mathrm{II}}$ on the adsorption of different phosphonates on GFH. Two different molar ratios of Ca:phosphonate, 0:1 and 2:1, at different $\mathrm{pH}$ values were considered. Table 2 shows the phosphonate concentrations used in Experiment 1, which was conducted with and without adsorbent to investigate the relevance of precipitation $\left(\mathrm{T}=20^{\circ} \mathrm{C} ; \mathrm{pH} 5,6,7,8,9,10\right.$, and $12 ; \mathrm{t}_{\mathrm{c}}=7 \mathrm{~d}$; initial concentration $=16.1 \mathrm{mg} / \mathrm{L}$ HPAA, PBTC, HEDP, NTMP, EDTMP, or DTPMP; Ca:phosphonate $0: 1$ and 2:1; $0.2 \mathrm{~g} \mathrm{GFH/L}$ and without GFH).

The objective of Experiment 2 was to examine the influence of $\mathrm{Ca}^{\mathrm{II}}$ on the adsorption of NTMP and DTPMP at higher $\mathrm{Ca}^{\mathrm{II}}$ concentrations than in Experiment 1 . These two phosphonates were selected as salient representatives of organophosphonates, as they are widely used in industrial applications, and the membrane concentrate investigated in this study contained DTPMP. The experiment was performed at seven different $\mathrm{pH}$ values and seven different molar ratios of $\mathrm{Ca}$ :phosphonate. These were: 0:1, 1:1, 2:1, 3.67:1, 5:1, 7.33:1, and 18.33:1. The adsorption process was investigated both with FerroSorp RW and without adsorbent to investigate the relevance of precipitation $\left(\mathrm{T}=20^{\circ} \mathrm{C} ; \mathrm{pH} 5,6,7,8,9,10\right.$, 
and $12 ; \mathrm{t}_{\mathrm{c}}=7 \mathrm{~d}$; initial concentration $=16.1 \mathrm{mg} / \mathrm{L} \mathrm{NTMP}$ or DTPMP; Ca:phosphonate 0:1-18.33:1; 0.2 g $\mathrm{GFH} / \mathrm{L}$ and without GFH).

Table 2. Different concentrations of phosphonates used in Experiment 1.

\begin{tabular}{cccc}
\hline & \multicolumn{2}{c}{ Phosphonate } \\
$\mathbf{m g} / \mathbf{L}$ & $\boldsymbol{\mu m o l} / \mathbf{L}$ & $\begin{array}{c}\text { Phosphonate-P } \\
\mathbf{m g} / \mathbf{L}\end{array}$ \\
\hline HPAA & 16.1 & 103 & 3.19 \\
PBTC & 16.1 & 59.6 & 1.85 \\
HEDP & 16.1 & 78.1 & 4.84 \\
NTMP & 16.1 & 53.8 & 5.00 \\
EDTMP & 16.1 & 36.9 & 4.57 \\
DTPMP & 16.1 & 28.1 & 4.35 \\
\hline
\end{tabular}

The aim of Experiment 3 was to investigate at which phosphonate and $\mathrm{Ca}^{\mathrm{II}}$ concentrations and molar Ca:phosphonate ratios phosphonates can be removed without the dosing of GFH, and which factors are decisive in this process. At pH 8 and 9, the NTMP and DTPMP concentrations 3.22 mg/L, $16.1 \mathrm{mg} / \mathrm{L}, 32.2 \mathrm{mg} / \mathrm{L}$, and $80.5 \mathrm{mg} / \mathrm{L}$ (Table 3) with the molar Ca:phosphonate ratios 0:1, 1:1, 2:1, 5:1, 10:1, 25:1, and 60:1 were examined $\left(\mathrm{T}=20^{\circ} \mathrm{C} ; \mathrm{pH} 8\right.$ and $9 ; \mathrm{t}_{\mathrm{c}}=7 \mathrm{~d}$; initial concentration $=3.22-80.5 \mathrm{mg} / \mathrm{L}$ NTMP or DTPMP; Ca:phosphonate 0:1-60:1; without GFH). Additionally, the five highest calcium concentrations were investigated using the same procedure, but in the absence of NTMP and DTPMP, to test possible precipitation of $\mathrm{CaCO}_{3}$ and $\mathrm{Ca}(\mathrm{OH})_{2} \cdot \mathrm{Ca}^{2+}$ concentrations before $\left(\mathrm{Ca}_{\text {start }}\right)$ and after $\left(\mathrm{Ca} \mathrm{a}_{\mathrm{end}}\right)$ the contact time were determined from the filtrate. This experiment was carried out using a duplicate approach.

Table 3. Different concentrations of phosphonates used in Experiment 3.

\begin{tabular}{cccc}
\hline & \multicolumn{2}{c}{ Phosphonate } \\
$\mathbf{m g} / \mathbf{L}$ & $\boldsymbol{\mu \mathbf { m o l } / \mathbf { L }}$ & $\begin{array}{c}\text { Phosphonate-P } \\
\mathbf{m g} / \mathbf{L}\end{array}$ \\
\hline \multirow{4}{*}{ NTMP } & 3.22 & 10.8 & 1.0 \\
& 16.1 & 53.8 & 5.0 \\
& 32.2 & 108 & 10 \\
& 80.5 & 269 & 25 \\
\hline \multirow{5}{*}{ DTPMP } & 3.22 & 5.61 & 0.9 \\
& 16.1 & 28.1 & 4.4 \\
& 32.2 & 56.1 & 8.7 \\
\hline
\end{tabular}

Experiment 4 focused on the membrane concentrate from a drinking water treatment plant, and on its synthetic replicas. The membrane concentrate was reproduced synthetically step by step to investigate the influence of different ions $\left(\mathrm{T}=20^{\circ} \mathrm{C}\right.$; $\mathrm{pH} 5,6,7,8,9,10$, and $12 ; \mathrm{t}_{\mathrm{c}}=7 \mathrm{~d}$; for the initial concentration see Chapter 2.3; $0.1 \mathrm{~g} \mathrm{GFH/L}$ and without GFH).

PHREEQC Interactive 3 with the Minteq.v4 database was used to predict possible precipitates.

\subsection{Analytical Methods}

For phosphorus analysis, a modification of the ISO 6878 [25] method was used ( ISO $_{\text {mini }}$ ). The $\mathrm{ISO}_{\text {mini }}$ molybdenum blue method has been described in detail by Rott et al. [22]. Prior to analysis, all glass materials that came into contact with the sample were thoroughly rinsed with $10 \%$ hydrochloric acid and deionized water. Digestion was performed in a HachLange HT200S thermostat. Absorbance measurements were carried out with a Nanocolor UV/VIS II spectrophotometer from Macherey-Nagel. A WTW SenTix $81 \mathrm{pH}$ electrode in combination with the WTW pH91 instrument was used to determine the $\mathrm{pH}$. In order to determine $\mathrm{Ca}^{2+}$, DIN 38406-3 was used [26]. A total sample volume of $50 \mathrm{~mL}$ of the solution to be analyzed was transferred into an Erlenmeyer flask with a 
volumetric pipette. A total of $2 \mathrm{~mL}$ of $2 \mathrm{M}$ sodium hydroxide solution and a spatula tip of indicator were added to the flask. The solution was titrated with $0.01 \mathrm{M}$ ethylenediaminetetraacetic acid (EDTA) solution while stirring, until the color changed completely.

\section{Results and Discussion}

\subsection{Experiment 1-Adsorption Behavior of Six Phosphonates in the Presence of and Absence of Ca ${ }^{I I}$}

Figure 2 enables a comparison of the adsorption behavior of six different phosphonates at molar Ca:phosphonate ratios of 0:1 and 2:1, with a contact time of seven days and different $\mathrm{pH}$ values. Additionally, the removal rates in the absence of GFH are shown, in order to determine the relevance of precipitation. The phosphonates in Figure 2 were sorted in the order of the increasing number of phosphonate groups (PG): HPAA (1 PG), PBTC (1 PG), HEDP (2 PG), NTMP (3 PG), EDTMP (4 PG), DTPMP (5 PG).

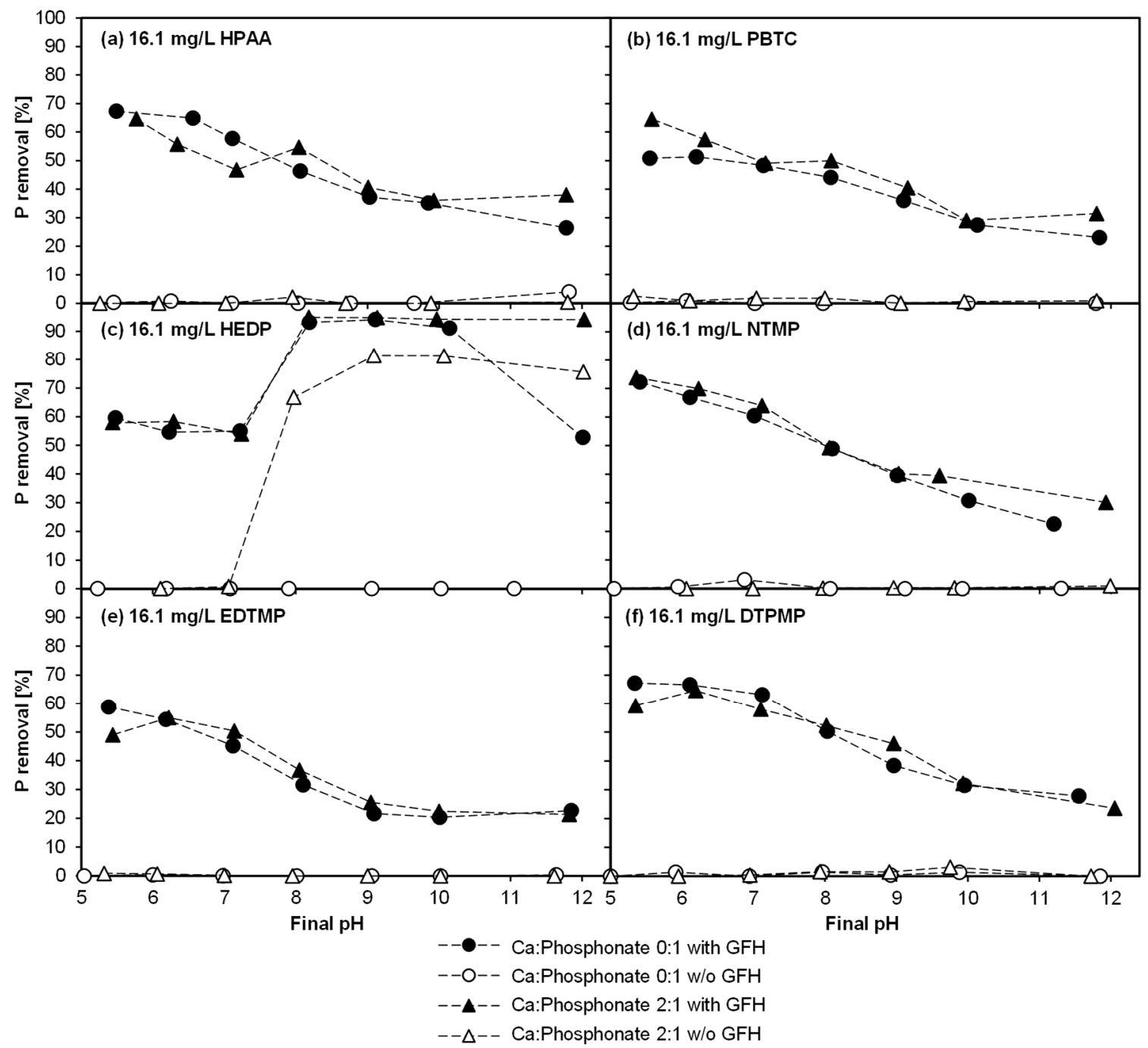

Figure 2. Influence of $\mathrm{Ca}^{\mathrm{II}}$ presence on phosphonate adsorption $\left(\mathrm{T}=20^{\circ} \mathrm{C} ; \mathrm{t}_{\mathrm{c}}=7 \mathrm{~d}\right.$; initial phosphonate concentration $=16.1 \mathrm{mg} / \mathrm{L} ; 0.2 \mathrm{~g} \mathrm{GFH} / \mathrm{L}$ and without GFH). (a) $16.1 \mathrm{mg} / \mathrm{L} \mathrm{HPAA,} \mathrm{(b)} 16.1 \mathrm{mg} / \mathrm{L} \mathrm{PBTC \text {, }}$ (c) $16.1 \mathrm{mg} / \mathrm{L}$ HEDP, (d) $16.1 \mathrm{mg} / \mathrm{L}$ NTMP, (e) $16.1 \mathrm{mg} / \mathrm{L}$ EDTMP, (f) $16.1 \mathrm{mg} / \mathrm{L} \mathrm{DTPMP.}$

For all phosphonates, except HEDP, the removal rates decreased with increasing $\mathrm{pH}$ to a similar extent (removal rates at $\mathrm{pH}_{\text {target }} 5$ and 12): HPAA from $67 \%$ to $27 \%$, PBTC $65 \%$ to $23 \%$, NTMP $74 \%$ to $23 \%$, EDTMP $59 \%$ to $24 \%$, DTPMP $66 \%$ to $24 \%$. The difference in the removal rate between the solutions 
in the presence of and absence of $\mathrm{Ca}^{\mathrm{II}}$ was always less than $13 \%$. Therefore, no major influence of $\mathrm{Ca}^{\mathrm{II}}$ on phosphonate removal was observed. This stands in contradiction to several previous studies. Nowack and Stone [21] investigated the adsorption of HEDP, NTMP, EDTMP, and DTPMP on goethite and found that excess $\mathrm{Ca}^{\mathrm{II}}$ concentrations significantly increased the maximum loading. Even at an equimolar Ca:NTMP ratio, the maximum loading for NTMP almost doubled. Similarly, Boels et al. [4] observed a near doubling of the maximum loading of GFH at a molar Ca:NTMP ratio of 2:1. At a molar ratio of 60:1, it was possible to increase the loading even further. Rott et al. [27] also found a positive influence of $\mathrm{Ca}^{\mathrm{II}}$ on the adsorption of NTMP and DTPMP on magnetic adsorbent particles (ZnFeZr-oxyhydroxide). In addition, Chen et al. [17] found a positive influence of the hardness ions calcium and magnesium on NTMP adsorption on GFH. The aforementioned studies attribute this behavior mainly to the potential formation of ternary complexes. Ternary complexes can build a bridge between the GFH surface and phosphonates, leading to an increased adsorption $[4,19,20]$.

In the batches without GFH, no removal could be detected. Thus, for this experiment, precipitation can be excluded as the cause of phosphorus removal. HEDP, however, deviated clearly from the behavior of the other phosphonates. In the presence of $\mathrm{GFH}$, it showed a removal of $60 \%\left(\mathrm{pH}_{\text {target }} 5\right)$ to $53 \%$ ( $\left.\mathrm{pH}_{\text {target }} 12\right)$, whereas the removal at $\mathrm{pH}_{\text {target }} 8$ to 10 was $>90 \%$.

A closer look at the behavior of HEDP reveals two particularly noteworthy aspects. First, with a molar Ca:phosphonate ratio of 2:1, phosphorus was removed even in the absence of GFH, and second, in the presence of GFH, phosphorus was removed without the addition of $\mathrm{Ca}^{\mathrm{II}}$. In the latter case, about $67 \%$ of the phosphorus was removed at $\mathrm{pH} 8.0$, about $81 \%$ at $\mathrm{pH} 9.1$ and 10.1 , and about $76 \%$ at $\mathrm{pH}$ 12.0. The removal of phosphorus even without the dosing of GFH suggests precipitation of $\mathrm{CaCO}_{3}$ or Ca-HEDP complexes. According to calculations performed with PHREEQC, at a calcium concentration of $156.2 \mu \mathrm{mol} / \mathrm{L}$, more than $7.2 \mathrm{mmol} / \mathrm{L}$ of (hydrogen-)carbonate would be necessary to precipitate $\mathrm{CaCO}_{3}$ at $\mathrm{pH}$ 8.0. These calculations do not consider HEDP, which complexes at least parts of the $\mathrm{Ca}$ II and additionally inhibits precipitation of $\mathrm{CaCO}_{3}[12,28]$. Since deionized water was used in the experiments, and the samples were rotated in closed centrifuge tubes (closed system), the (hydrogen-)carbonate content (from airborne $\mathrm{CO}_{2}$ ) of the solutions is expected to be low. Therefore, the formation of $\mathrm{CaCO}_{3}$ is unlikely.

Another explanation for the observed HEDP elimination in the absence of GFH could be the precipitation of Ca-HEDP complexes. Several researchers have investigated various different calcium-phosphonate precipitates, such as Ca-HEDP [29], Ca-NTMP [16,30], and Ca-DTPMP [31]. However, these studies were conducted using relatively high phosphonate concentrations. In another study, Zhang et al. [32] found more Ca-phosphonate precipitation for HEDP as compared with other phosphonates. The authors concluded that the order of solubility of the Ca-phosphonate complexes was as follows: PBTC > DTPMP > EDTMP > NTMP > HEDP. This corresponds with the results of the current study and the findings of Amjad et al. [33], who found a calcium ion tolerance of PBTC $>>$ HEDP.

Interestingly, between $\mathrm{pH} 8$ and 10, a peak in phosphorus removal was observed without the addition of $\mathrm{Ca}^{\mathrm{II}}$. The reason for this could be the dissolution of calcium from the GFH. The re-dissolved $\mathrm{Ca}^{\mathrm{II}}$ could then lead to precipitation. To investigate this in more detail, a $0.01 \mathrm{M}$ CAPSO solution at $\mathrm{pH} 9$ with $0.2 \mathrm{~g} / \mathrm{L}$ GFH was rotated with a contact time of seven days (without a phosphonate). $\mathrm{A} \mathrm{Ca}^{2+}$ concentration of $11.0 \pm 1.1 \mathrm{mg} / \mathrm{L}$ could then be observed in the membrane-filtered supernatant. According to the manufacturer's statement specifying $\geq 12-19 \%$ calcium content in the GFH, a dosage of $0.2 \mathrm{~g} / \mathrm{L} \mathrm{GFH}$ would result in a maximum calcium concentration in the solution of 24 to $38 \mathrm{mg} / \mathrm{L}$, if completely re-dissolved. Therefore, it can be assumed that approx. $29 \%$ to $46 \%$ of the $\mathrm{Ca}^{\mathrm{II}}$ was re-dissolved.

Those measurements may explain why no positive effect of $\mathrm{Ca}^{\mathrm{II}}$ on the removal of phosphorus was observed with the other five phosphonates. A calcium concentration of $11.0 \mathrm{mg} / \mathrm{L}$ (as re-dissolved from the GFH) already corresponds to the following molar Ca:phosphonate ratios: Ca:HPAA 2.7:1, Ca:PBTC 4.6:1, Ca:HEDP 3.5:1, Ca:NTMP 5.1:1, Ca:EDTMP 7.5:1, and Ca:DTPMP 9.9:1. Therefore, although 
no $\mathrm{Ca}^{\mathrm{II}}$ was added, the positive effect of $\mathrm{Ca}^{\mathrm{II}}$ had probably already been achieved by re-dissolution from the GFH. This shows the important role of the $\mathrm{CaCO}_{3}$ content of the GFH and also explains the deviation between these results and those found in previous publications.

In conclusion, Experiment 1 yielded two findings: First, the re-dissolved calcium from the GFH had a positive effect on phosphonate adsorption, possibly attributable to the formation of ternary complexes. Second, at the given conditions, HEDP was found to precipitate presumably as Ca-phosphonate complexes, which also increases its elimination rate.

\subsection{Experiment 2-Adsorption Behavior of NTMP and DTPMP in the Presence of $C a^{I I}$ in Higher Concentrations}

The aim of Experiment 2 was to investigate the influence of $\mathrm{Ca}^{\mathrm{II}}$ in higher concentrations than those in Experiment 1 on the adsorption of NTMP and DTPMP on GFH. Figure 3 shows the results of batches with NTMP and DTPMP in the presence of and absence of GFH over different $\mathrm{pH}$ values from 5 to 12 .

According to Figure $3 b$, in the batches without adsorbent, no removal of NTMP took place up to a molar Ca:NTMP ratio of 7.33:1. A different behavior was observed when $\mathrm{Ca}^{\mathrm{II}}$ was added in a molar Ca:NTMP ratio of 18.33:1. NTMP was removed at particular $\mathrm{pH}$ values: $\sim 89 \%$ at $\mathrm{pH} 8.1, \sim 93 \%$ at $\mathrm{pH}$ 9.0, $98 \%$ at $\mathrm{pH} 9.8$, and $\sim 28 \%$ at $\mathrm{pH} 12.0$. A possible explanation for this behavior could be $\mathrm{CaCO}_{3}$ or Ca-NTMP precipitation. According to calculations performed with PHREEQC, more than $0.8 \mathrm{mmol} / \mathrm{L}$ of (hydrogen-)carbonate would be necessary at a calcium concentration of $986.3 \mu \mathrm{mol} / \mathrm{L}$ to precipitate $\mathrm{CaCO}_{3}$ at $\mathrm{pH}$ 8.1. These calculations do not consider NTMP, which complexes at least parts of the $\mathrm{Ca}^{\mathrm{II}}$ and inhibits precipitation of $\mathrm{CaCO}_{3}[12,13]$. The (hydrogen-)carbonate content of the solutions should be low due to the use of deionized water in the experiments, and due to the rotation of the samples in closed centrifuge tubes (closed system). Thus, the formation of $\mathrm{CaCO}_{3}$ is unlikely.

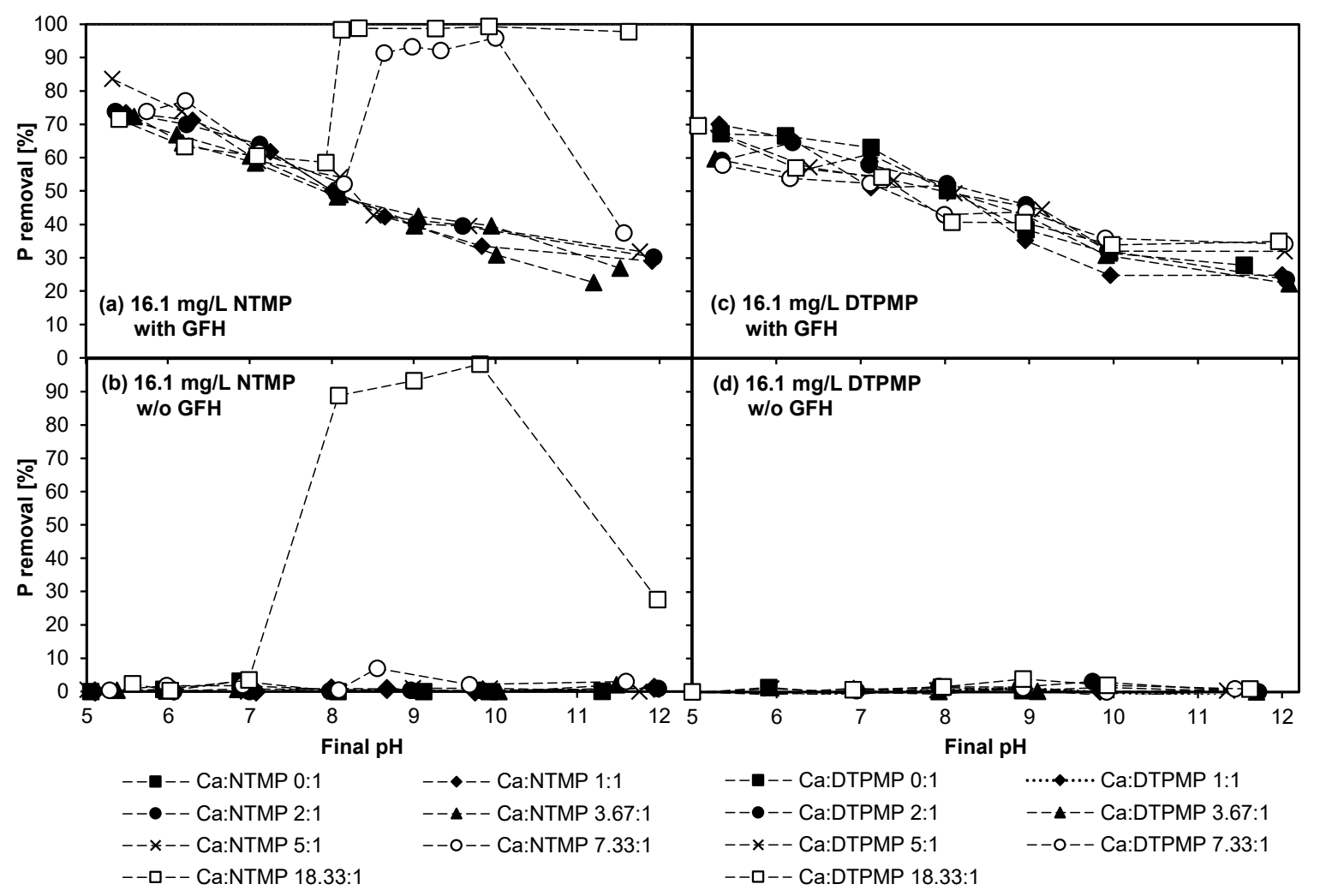

Figure 3. Influence of various molar Ca:phosphonate ratios on phosphonate adsorption $\left(\mathrm{T}=20^{\circ} \mathrm{C} ; \mathrm{t}_{\mathrm{c}}\right.$ $=7 \mathrm{~d}$; initial concentration $=16.1 \mathrm{mg} / \mathrm{L}$ phosphonate; $0.2 \mathrm{~g} \mathrm{GFH} / \mathrm{L}$ and without GFH). (a) $16.1 \mathrm{mg} / \mathrm{L}$ NTMP with GFH, (b) $16.1 \mathrm{mg} / \mathrm{L}$ NTMP without GFH, (c) $16.1 \mathrm{mg} / \mathrm{L}$ DTPMP with GFH, (d) $16.1 \mathrm{mg} / \mathrm{L}$ DTPMP without GFH. 
In the case of added GFH adsorbent (Figure 3a), the adsorption of NTMP was nearly identical at molar Ca:NTMP ratios of up to 5:1. At a molar ratio of 7.33:1, between $\mathrm{pH} 8.5$ and 10.0, and at 18.33:1, between $\mathrm{pH} 8.1$ and 11.6, increased removal occurred. Interestingly, when comparing the batches with (Figure 3a) and without (Figure 3b) GFH, a discrepancy can be observed. If precipitates were the reason for an increased removal, a removal of phosphorus should have also been seen at a molar Ca:NTMP ratio of 7.33:1 from $\mathrm{pH} 8.5$ to 10.0 and at a molar ratio of 18.33:1 at $\mathrm{pH} 12$, as observed in the batches without GFH. However, this can be explained again by the re-dissolution of calcium from the GFH, which may have led to a higher availability of $\mathrm{Ca}^{\mathrm{II}}$ in the batches with $\mathrm{GFH}$ than indicated by the molar ratios in Figure 3.

In Figure 3c,d the behavior of DTPMP is shown. In the batches without GFH (Figure 3d), no removal of DTPMP took place throughout all $\mathrm{pH}$ values and all molar Ca:DTPMP ratios tested. Therefore, a precipitation of $\mathrm{CaCO}_{3}$ or Ca-DTPMP can be excluded. It is known that DTPMP, unlike other organophosphonates such as HEDP, NTMP, and EDTMP, does not precipitate as 1:1 complexes [34]. The batches with DTPMP and GFH (Figure 3c) show the typical behavior of phosphonates on iron-containing surfaces, namely a decreasing adsorption capacity with increasing $\mathrm{pH}[3,18,21,35]$. The differences in phosphorus removal among the different molar Ca:DTPMP ratios do not show any pattern; therefore, they must have been due to inaccuracies that commonly arise when conducting experiments. Certain deviations in the results of these experiments are to be expected, since some of the input variables may already differ slightly, such as the weighed adsorbent mass, homogeneity of the GFH, $\mathrm{pH}_{\text {end }}$ value, and so on. Repetitions of selected batches produced similar results (not shown in the figures for better readability). However, despite these deviations, tendencies can still be clearly identified.

In conclusion, the batches with NTMP showed precipitation, which presumably consisted of Ca-NTMP complexes, whereas the batches with DTPMP did not show any precipitation. This corresponds with data found in the literature: Zhang et al. [32] observed that Ca-NTMP complexes have a lower solubility than Ca-DTPMP complexes. Furthermore, Gledhill and Feijtel [36] stated that Ca-NTMP complexes have higher stability constants than Ca-DTPMP complexes at any given $\mathrm{pH}$. Taken together, these conclusions indicate that there are more Ca-NTMP than Ca-DTPMP complexes at any given $\mathrm{pH}$, but the solubility of the Ca-NTMP complexes is lower.

\subsection{Experiment 3-Investigations on NTMP and DTPMP Precipitation}

Since the previous experiments had shown that precipitation is responsible for increased elimination, the aim of Experiment 3 was to investigate this phenomena in more detail. The experiment was necessary because it does not seem to be possible to predict the precipitation of Ca-phosphonate complexes on the basis of the existing data. Depending on the experimental conditions (molar Ca:phosphonate ratio, $\mathrm{pH}$, ionic strength, temperature) different complexes can precipitate [30,31], but reliable solubility products have been published only for some of them. In addition, the presence of calcium can have an effect on the $\mathrm{pK}_{\mathrm{a}}$ values of the phosphonates [29]. Additionally, a critical evaluation showed that the stability constants of DTPMP are not reliable, due to difficulties in synthesis and purification [34].

Different phosphonate concentrations and molar Ca:phosphonate ratios were applied (Tables 4 and 5). The pH values 8 and 9 were examined, as the previously described increased removal of phosphonates started in this $\mathrm{pH}$ range. Higher $\mathrm{pH}$ values were not investigated, because lower $\mathrm{pH}$ values are recommended for the adsorption of phosphonates on GFH [18]. In Tables 4 and 5, removal rates higher than $90 \%$ are highlighted in dark gray, and removal rates $\geq 5 \%$ and $\leq 90 \%$ are highlighted in light gray. Removal rates of less than 5\% were considered to be measurement inaccuracies, as were negative values (which were within the $5 \%$ inaccuracy range). Standard deviations are shown in Tables S1 and S2. Calcium concentrations that are discussed separately are highlighted in bold type. 
Table 4. Removal of NTMP by precipitation at different calcium concentrations and $\mathrm{pH}$ values $(\mathrm{T}=20$ ${ }^{\circ} \mathrm{C} ; \mathrm{t}_{\mathrm{c}}=7 \mathrm{~d} ;$ no GFH added). Standard deviations are shown in Table S1.

\begin{tabular}{|c|c|c|c|c|c|c|c|c|c|c|c|c|}
\hline & \multicolumn{12}{|c|}{ NTMP [mg/L] } \\
\hline & 3.22 & 16.1 & 32.2 & 80.5 & 3.22 & 16.1 & 32.2 & 80.5 & 3.22 & 16.1 & 32.2 & 80.5 \\
\hline & \multicolumn{4}{|c|}{ Calcium [mmol/L] } & \multicolumn{4}{|c|}{ Removal at pH 8 [\%] } & \multicolumn{4}{|c|}{ Removal at pH 9 [\%] } \\
\hline Ca:NTMP 0:1 & 0.00 & 0.00 & 0.00 & 0.00 & 1 & 0 & 1 & 0 & 3 & 0 & 1 & 2 \\
\hline Ca:NTMP 1:1 & 0.01 & 0.05 & 0.11 & 0.27 & 3 & 0 & 2 & 1 & -1 & 0 & 1 & 2 \\
\hline Ca:NTMP 2:1 & 0.02 & 0.11 & 0.22 & 0.54 & 1 & 0 & 1 & 1 & 0 & 1 & 2 & 91 \\
\hline Ca:NTMP 5:1 & 0.05 & 0.27 & 0.54 & 1.35 & 2 & 1 & 2 & 99 & 4 & 2 & 78 & 99 \\
\hline Ca:NTMP 10:1 & 0.11 & 0.54 & 1.08 & 2.69 & 1 & 3 & 95 & 99 & 4 & 64 & 100 & 100 \\
\hline Ca:NTMP 25:1 & 0.27 & 1.35 & 2.69 & 6.73 & 1 & 94 & 99 & 100 & 3 & 97 & 100 & 100 \\
\hline Ca:NTMP 60:1 & 0.65 & 3.23 & 6.46 & 16.1 & 0 & 97 & 99 & 100 & 2 & 99 & 100 & 100 \\
\hline
\end{tabular}

Table 4 shows the results of the batches with NTMP at different calcium concentrations. In the batches without $\mathrm{Ca}^{\mathrm{II}}$ and with a molar Ca:NTMP ratio of 1:1, no removal of phosphorus was observed. The same applies to the batches with $3.22 \mathrm{mg} / \mathrm{L}$ NTMP at all molar Ca:NTMP ratios. At higher NTMP concentrations, phosphorus was removed almost completely above particular calcium concentrations. At $\mathrm{pH}$ 9, the removal started at lower molar Ca:NTMP ratios than at pH 8 (e.g., with $80.5 \mathrm{mg} / \mathrm{L}$ NTMP at $\mathrm{pH}$ 9, a molar Ca:NTMP ratio of 2:1 was sufficient for an elimination of $91 \%$, whereas at $\mathrm{pH} 8$ no removal occurred).

The three batches with the same $\mathrm{Ca}^{\mathrm{II}}$ concentration of $0.54 \mathrm{mmol} / \mathrm{L}$ highlight an interesting aspect (highlighted in bold type). The NTMP removal at $\mathrm{pH} 9$ increased with increasing NTMP concentration from $64 \pm 0.4 \%$ at $16.1 \mathrm{mg} / \mathrm{L}$, and $78 \pm 1.9 \%$ at $32.2 \mathrm{mg} / \mathrm{L}$, up to $91 \pm 0.2 \%$ at $80.5 \mathrm{mg} / \mathrm{L}$. This indicates a precipitation of Ca-NTMP complexes, since a possible precipitation of $\mathrm{CaCO}_{3}$ would have been inhibited by increasing concentrations of NTMP, due to its scale inhibition effect [13].

In Table 5 the results of the DTPMP batches at different calcium concentrations are shown. At molar Ca:DTPMP ratios of up to 2:1 and at $3.22 \mathrm{mg} / \mathrm{L}$ DTPMP, no removal of phosphorus was observed. At higher DTPMP concentrations, however, phosphorus was at least partially removed at particular $\mathrm{Ca}^{\mathrm{II}}$ concentrations. Similar to NTMP, at pH 9, DTPMP was eliminated at lower molar Ca:DTPMP ratios than at $\mathrm{pH} 8$.

Table 5. Removal of DTPMP by precipitation at different calcium concentrations and $\mathrm{pH}$ values $(\mathrm{T}=20$

${ }^{\circ} \mathrm{C} ; \mathrm{t}_{\mathrm{c}}=7 \mathrm{~d}$; no GFH added). Standard deviations are shown in Table S2.

\begin{tabular}{|c|c|c|c|c|c|c|c|c|c|c|c|c|}
\hline & \multicolumn{12}{|c|}{ DTPMP [mg/L] } \\
\hline & 3.22 & 16.1 & 32.2 & 80.5 & 3.22 & 16.1 & 32.2 & 80.5 & 3.22 & 16.1 & 32.2 & 80.5 \\
\hline & \multicolumn{4}{|c|}{ Calcium [mmol/L] } & \multicolumn{4}{|c|}{ Removal at pH 8 [\%] } & \multicolumn{4}{|c|}{ Removal at pH 9 [\%] } \\
\hline Ca:DTPMP 0:1 & 0.00 & 0.00 & 0.00 & 0.00 & -2 & -1 & -1 & -1 & -2 & 0 & 2 & -1 \\
\hline Ca:DTPMP 1:1 & 0.01 & 0.03 & 0.06 & 0.14 & -1 & 1 & -4 & -1 & 2 & 0 & 4 & 0 \\
\hline Ca:DTPMP 2:1 & 0.01 & 0.06 & 0.11 & 0.28 & 0 & -1 & -4 & -1 & -1 & 0 & -2 & 0 \\
\hline Ca:DTPMP 5:1 & 0.03 & 0.14 & 0.28 & 0.70 & 0 & 1 & 0 & 0 & -1 & 0 & -1 & 62 \\
\hline Ca:DTPMP 10:1 & 0.06 & 0.28 & 0.56 & 1.40 & 0 & 0 & 0 & 74 & -4 & 0 & 47 & 91 \\
\hline Ca:DTPMP 25:1 & 0.14 & 0.70 & 1.40 & 3.51 & -1 & -1 & 56 & 90 & -1 & $\mathbf{0}$ & 88 & 94 \\
\hline Ca:DTPMP 60:1 & 0.34 & 1.68 & 3.37 & 8.42 & 0 & 54 & 84 & 93 & -6 & 85 & 92 & 96 \\
\hline
\end{tabular}

At pH 8 and $16.1 \mathrm{mg} / \mathrm{L}$ DTPMP, a removal of $54 \%$ was observed at a molar Ca:DTPMP ratio of 60:1. At a concentration of $12 \mathrm{mM} \mathrm{Ca}$ and $0.73 \mu \mathrm{M}$ DTPMP $(0.42 \mathrm{mg} / \mathrm{L})$ at $70{ }^{\circ} \mathrm{C}$, Kan et al. [31] found a crystalline Ca-DTPMP precipitate. Yan et al. [37] also assumed precipitation of a Ca-DTPMP complex in their experiments with residual concentrations of $0.06 \mathrm{mM}$ DTPMP and approx. $0.8 \mathrm{mM}$ calcium.

An increased removal rate of DTPMP was observed at a constant $\mathrm{Ca}^{\mathrm{II}}$ concentration of $0.70 \mathrm{mmol} / \mathrm{L}$, paralleled by increasing DTPMP concentrations (Table 5) (i.e., at $\mathrm{pH} 9$; no elimination was found at $16.1 \mathrm{mg} / \mathrm{L}$ DTPMP, but at $80.5 \mathrm{mg} / \mathrm{L}$ DTPMP, $62 \pm 1.9 \%$ was eliminated). Moreover, at $\mathrm{pH} 8$, 
at a $\mathrm{Ca}{ }^{\mathrm{II}}$ concentration of $1.40 \mathrm{mmol} / \mathrm{L}$ and $32.2 \mathrm{mg} / \mathrm{L}$ DTPMP, $56 \pm 1.4 \%$ was removed, whereas at $80.5 \mathrm{mg} / \mathrm{L}$ DTPMP, a higher removal rate of $74 \pm 0.3 \%$ was observed. This indicates that precipitation of Ca-DTPMP complexes occurred, as it was observed for NTMP (Table 4).

The results of Experiment 3 match the results from Experiment 2, in which the same concentration of $16.1 \mathrm{mg} / \mathrm{L}$ NTMP and DTPMP was used. In conclusion, NTMP and DTPMP demonstrated similar behavior. However, at comparable molar Ca:phosphonate ratios, NTMP showed a higher removal than DTPMP. This corresponds with the findings of Zhang et al. [32], who found the solubility of Ca-DTPMP complexes to be higher than that of Ca-NTMP complexes.

To gain more knowledge as to which substances are precipitated, further batches were investigated with the five highest $\mathrm{Ca}^{\mathrm{II}}$ concentrations used in Experiment 3 in the absence of phosphonate. In this case, the calcium concentration was measured in the membrane filtrate after seven days of rotation (Table 6$)$. $\mathrm{Ca}_{\text {start }}$ deviated only $\pm 3.4 \%$ from the target calcium concentration $\left(\mathrm{Ca}_{\text {target }}\right)$. Therefore, this deviation is assumed to represent the degree of measurement inaccuracy inherent in this calcium determination method.

Table 6. Change in calcium concentration in the absence of phosphonates $\left(\mathrm{T}=20^{\circ} \mathrm{C} ; \mathrm{pH}=8\right.$ and $9 ; \mathrm{t}_{\mathrm{c}}=$ $7 \mathrm{~d}$; no GFH added). Catarget: target starting concentration, $\mathrm{Ca}_{\text {start }}$ : actual starting concentration, $\mathrm{Ca}_{\text {end }}$ : final concentration, Deviation: $\mathrm{Ca}_{\text {start }} / \mathrm{Ca}_{\text {end }}$.

\begin{tabular}{cccccc}
\hline $\mathbf{p H}_{\text {start }}$ & $\mathbf{p H}_{\text {end }}$ & $\mathbf{C a}_{\text {target }}[\mathbf{m m o l} / \mathbf{L}]$ & $\mathbf{C a}_{\text {start }}[\mathbf{m m o l} / \mathbf{L}]$ & $\mathbf{C a}_{\text {end }}[\mathbf{m m o l} / \mathbf{L}]$ & Deviation $[\%]$ \\
\hline 8.01 & 8.04 & 3.51 & 3.44 & 3.42 & 0.6 \\
7.99 & 8.00 & 6.46 & 6.35 & 6.40 & -0.8 \\
8.01 & 8.04 & 6.73 & 6.80 & 7.00 & -2.9 \\
8.00 & 8.03 & 8.42 & 8.40 & 8.20 & 2.4 \\
8.00 & 8.03 & 16.10 & 15.90 & 16.00 & -0.6 \\
9.01 & 9.01 & 3.51 & 3.60 & 3.64 & -1.0 \\
8.98 & 8.99 & 6.46 & 6.30 & 6.10 & 3.2 \\
9.01 & 9.02 & 6.73 & 6.50 & 6.40 & 1.5 \\
8.97 & 8.96 & 8.42 & 8.45 & 8.50 & -0.6 \\
8.99 & 8.97 & 16.10 & 15.60 & 15.35 & 1.6 \\
\hline
\end{tabular}

The initial and final $\mathrm{pH}$ values are nearly identical. A precipitation of $\mathrm{CaCO}_{3}$, however, would have resulted in a $\mathrm{pH}$ decrease (calculations performed with PHREEQC) that should have been noticeable, even though a buffer was used. The deviation between the initial and final concentration of $\mathrm{Ca}^{2+}$ varied between $-3 \%$ and $+3 \%$. The negative deviations are attributable to batches in which the measured final concentration was above the measured initial concentration. As this is not possible, the negative values indicate the measurement error of the analysis method. As the positive deviations are of the same order of magnitude, it is assumed that the deviations within this range are due to measurement inaccuracies, which is also in line with the deviations between $\mathrm{Ca}_{\text {start }}$ and $\mathrm{Ca}_{\text {target }}$ as mentioned above. It can be concluded that neither $\mathrm{CaCO}_{3}$ nor $\mathrm{Ca}(\mathrm{OH})_{2}$ precipitated. Since precipitation only occurred in the presence of the phosphonates, this is another indication that the precipitates were Ca-phosphonate complexes.

\subsection{Experiment 4-Adsorption Behavior of Membrane Concentrate and Its Synthetic Replicas}

\subsubsection{Adsorption of DTPMP and Orthophosphate}

The aim of Experiment 4 was to analyze the respective competitive or synergistic effects of ions on phosphorus removal. To this end, batch adsorption experiments with the real membrane concentrate and its synthetic replicas were conducted. For a better understanding of the results, they have been broken down as follows: Figure $4 \mathrm{a}$,b show the influence of anions in the presence of and absence of GFH, and Figure 4c,d show the influence of cations with and without GFH present. Figure 5 shows the results for orthophosphate with the same layout. 
The adsorption of DTPMP on GFH in the presence of negatively charged compounds is depicted in Figure 4a. As observed in previous studies [3,18,21,35], the adsorption capacity decreased with increasing $\mathrm{pH}$. Furthermore, in the mere presence of DTPMP (solution A), the elimination was higher than in all other combinations with anions. By comparing solution A (only DTPMP in the solution) with solution B (only orthophosphate in the solution, Figure 5a), a slightly higher adsorption of orthophosphate becomes apparent. This could be attributed to the large difference in molecular size.

In the presence of DTPMP and orthophosphate (solution C), the elimination of DTPMP was slightly suppressed. This is in line with the findings of Nowack and Stone [35], who observed the suppression of phosphate adsorption in the presence of phosphonates, and the lowering of phosphonate adsorption in the presence of phosphate.

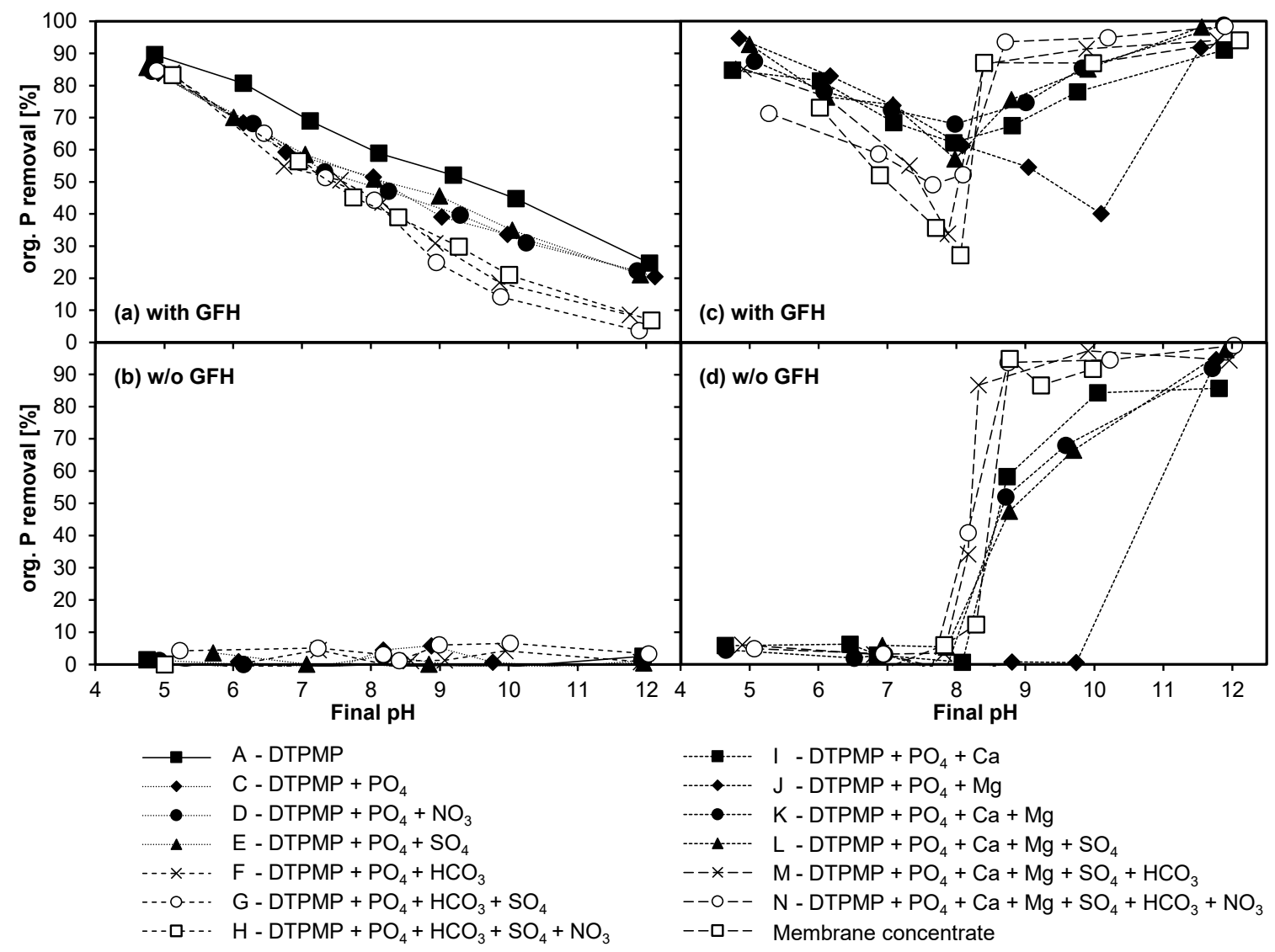

Figure 4. Organic $P$ removal from synthetic replicas and real membrane concentrate $\left(T=20^{\circ} \mathrm{C} ; \mathrm{t}_{\mathrm{c}}=7 \mathrm{~d}\right.$; initial concentrations: see Chapter 2.3; $0.1 \mathrm{~g} \mathrm{GFH/L}$ and without GFH). (a) solutions A, C-H with GFH, (b) solutions A, C-H without GFH, (c) solutions I-N and membrane concentrate with GFH, (d) solutions I-N and membrane concentrate without GFH.

\subsubsection{Influence of Anions}

When nitrate was added (solution D), no influence was observed. Although nitrate can adsorb on GFH [38], there seems to be no competition for the same adsorption sites. Similarly, Zelmanov and Semiat [39] could not detect any influence of nitrate on the adsorption of orthophosphate on iron oxide/hydroxide nanoparticle-based agglomerates.

The presence of sulfate (solution E, Figures $4 \mathrm{a}$ and 5a) also had no observable effect on the adsorption of phosphorus compounds. This is consistent with the results of Boels et al. [40], who found only a minor influence of sulfate on the adsorption of NTMP on waste filtration sand, and with Boels et al. [4], who observed no influence of sulfate ions on NTMP adsorption on GFH. Although only very few investigations have been published on the effect of sulfate on phosphonate adsorption, 
several studies have investigated the possible competitive adsorption of sulfate and orthophosphate. According to a study by Geelhoed et al. [41], in which the competitive adsorption of sulfate and orthophosphate on goethite was analyzed, phosphate proved to be much more competitive than sulfate, despite the ability of sulfate to form inner-sphere complexes. The presence of sulfate resulted only in a small decrease in phosphorus adsorption at $\mathrm{pH}<4$. Moreover, Violante et al. [42] also found that sulfate competed only poorly with orthophosphate for adsorption sites of minerals and soils at $\mathrm{pH}$ values above 5. Genz et al. [43] could not detect any influence of sulfate ions when a membrane bioreactor filtrate was spiked with sulfate prior to phosphorus removal with GFH. Thus, the results of the current study regarding the influence of nitrate und sulfate ions are in line with those found in the literature.

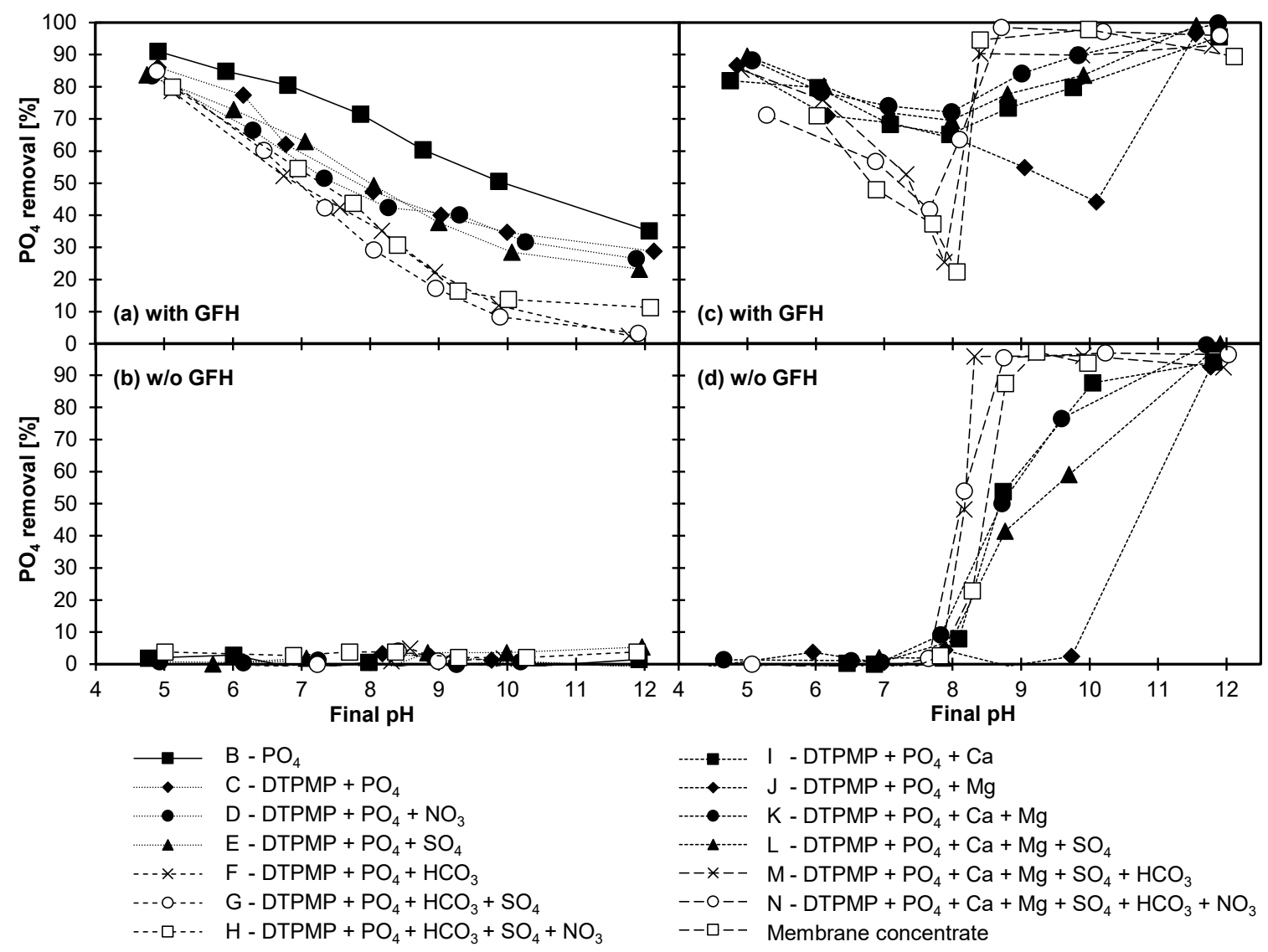

Figure 5. Phosphate removal from synthetic replicas and real membrane concentrate $\left(\mathrm{T}=20^{\circ} \mathrm{C} ; \mathrm{t}_{\mathrm{c}}=7 \mathrm{~d}\right.$; initial concentration see chapter 2.3; $0.1 \mathrm{~g} \mathrm{GFH/L}$ and without GFH). (a) solutions B-H with GFH, (b) solutions B-H without GFH, (c) solutions I-N and membrane concentrate with GFH, (d) solutions I-N and membrane concentrate without GFH.

With the addition of (hydrogen-)carbonate (solution F, Figures $4 \mathrm{a}$ and $5 \mathrm{a}$ ), the adsorption of organic phosphorus decreased slightly at $\mathrm{pH} 5$ to 7 , and distinctly from $\mathrm{pH} 8$ to 12. Boels et al. [40] found that (hydrogen-)carbonate ions interfered with the adsorption of NTMP at low concentrations. Another study conducted by $\mathrm{Su}$ and Suarez [44] found that (hydrogen-)carbonate lowered the electrophoretic mobility and reduced the $\mathrm{pH}_{\mathrm{PZC}}$ of iron oxide adsorbents, suggesting inner-sphere carbonate adsorption. Lowering the $\mathrm{pH}_{\mathrm{PZC}}$ would lead to greater electrostatic repulsion between DTPMP, which is highly negatively charged at high $\mathrm{pH}$ values, and GFH. A study investigating the adsorption of orthophosphate on iron oxide/hydroxide nanoparticle-based agglomerates showed a significant impact of (hydrogen-)carbonate concentration. Experiments with an initial P concentration of 10 ppm resulted in a residual $\mathrm{P}$ concentration of $<0.05 \mathrm{ppm}$ with no (hydrogen-)carbonate ions, and of $0.55 \mathrm{ppm}$ in the presence of $1250 \mathrm{ppm}$ (hydrogen-)carbonate ions (pH 7.5) [39]. This is also 
in line with the findings of Chitrakar et al. [45], who stated the order of selectivity for phosphate adsorption on goethite at $\mathrm{pH} 8$ as $\mathrm{Cl}^{-}, \mathrm{NO}_{3}{ }^{-}, \mathrm{SO}_{4}{ }^{2-}<<\mathrm{CO}_{3}{ }^{2-}, \mathrm{HPO}_{4}{ }^{2-}$. A study investigating the adsorption of carbonate found that phosphate has a higher affinity towards ferrihydrite than carbonate. A high concentration of carbonate ions was needed before a significant suppression of phosphate adsorption was observable, which increased with increasing $\mathrm{pH}$ [46]. In the current study, such a high concentration of (hydrogen-)carbonate ions was present. The increased competition for adsorption sites at $\mathrm{pH}>8$ could be attributed to the presence of divalent $\mathrm{CO}_{3}{ }^{2-}$ ions and the resulting greater electrostatic attraction. The additional presence of sulfate (solution $\mathrm{G}$ ) or sulfate and nitrate (solution $\mathrm{H}$ ) resulted in no further reduction of adsorption. Figures $4 \mathrm{~b}$ and $5 \mathrm{~b}$ show that, without $\mathrm{GFH}$, there was no noteworthy elimination of organic phosphorus and phosphate. Thus, precipitation can be excluded.

\subsubsection{Influence of Cations}

Figure $4 c, d$ and Figure $5 c$,d show the effect of the two hardness ions calcium and magnesium on the removal of DTPMP and phosphate in the presence of and absence of GFH. The figures also illustrate the effect of the two cations in combination with the previously investigated anions up to a near-complete synthetic replication of the membrane concentrate, as well as with the original membrane concentrate.

As shown in Figures $4 c$ and $5 c$, a noticeable change was observed with the addition of cations, indicating a possible synergistic interaction. The distinct tendency towards a drastically enhanced adsorption at $\mathrm{pH}$ values $>8$ even resulted in an elimination increase of up to $>60$ percentage points (e.g., at $\mathrm{pH} 12$, from $\sim 30 \%$ (solution $\mathrm{C}$ ) to $>90 \%$ in the presence of $\mathrm{Ca}^{\mathrm{II}}$ (solutions I to $\mathrm{N}$ )). However, at $\mathrm{pH}$ values $>8$, a removal was also observable without $\mathrm{GFH}$ (Figures $4 \mathrm{~d}$ and $5 \mathrm{~d}$ ). Thus, precipitation must have occurred in some form at $\mathrm{pH}>8$.

Interestingly, up to $\mathrm{pH} 8$, the combination of DTPMP, $\mathrm{PO}_{4}-\mathrm{P}$, and $\mathrm{Ca}^{\mathrm{II}}$ (solution I) resulted in a higher elimination of organic phosphorus than the combination of only DTPMP and $\mathrm{PO}_{4}-\mathrm{P}$ (solution $\mathrm{C}$ ). The higher elimination was comparable to the elimination achieved for solution A (mere presence of DTPMP). The same kind of effect was observed with the solution with additional $\mathrm{Mg}^{\mathrm{II}}$ (solution $\mathrm{J}$, up to $\mathrm{pH} 10$ ) and the solution with additional $\mathrm{Ca}^{\mathrm{II}}$ and $\mathrm{Mg}^{\mathrm{II}}$ combined (solution $\mathrm{K}$ ). $\mathrm{Up}$ to $\mathrm{pH} 8$, however, no removal by precipitation was observed in the absence of GFH (Figures $4 \mathrm{~d}$ and $5 \mathrm{~d}$ ). Thus, at $\mathrm{pH}<8$, the enhanced elimination by $\mathrm{Ca}^{\mathrm{II}}$ and $\mathrm{Mg}^{\mathrm{II}}$ ions must have been due mainly to the formation of ternary complexes [19]. These results stand in agreement with those of previous studies that have shown that excess $\mathrm{Ca}^{\mathrm{II}}$ concentrations can substantially increase the maximum surface coverage of phosphonates $[4,17,21,27]$. Various studies have attributed this behavior to the formation of ternary complexes. Excess magnesium is known to have similar effects [47].

\subsubsection{Combined Influence of Anions and Cations}

The additional presence of sulfate ions (solution L) did not lead to altered behavior. When (hydrogen-)carbonate was added to solutions with $\mathrm{Ca}^{\mathrm{II}}$ and $\mathrm{Mg}^{\mathrm{II}}$ (solutions $\mathrm{M}$ and $\mathrm{N}$ ), up to $\mathrm{pH} 8$, a lower removal of organic phosphorus and $\mathrm{PO}_{4}-\mathrm{P}$ was observed as compared with other solutions containing cations (solutions I to L). This supports the already noted assumption that (hydrogen-)carbonate is a competing ion for phosphonates.

Above $\mathrm{pH}$ 8, on the other hand, even in the absence of GFH, organic phosphorus and $\mathrm{PO}_{4}-\mathrm{P}$ was eliminated (Figures $4 \mathrm{~d}$ and $5 \mathrm{~d}$ ). This proves that the elimination observed in this $\mathrm{pH}$ range in the presence of GFH must have at least in part been attributable to precipitation. A calcium concentration of $15.3 \mathrm{mmol} / \mathrm{L}$ in solutions I to $\mathrm{N}$ resulted in a molar Ca:DTPMP ratio of about 3200:1. This very high ratio was not investigated in Experiment 3, but given the tendency of the results in Table 5, it seems possible that above a certain molar Ca:DTPMP ratio, precipitation will occur even at low DTPMP concentrations. Furthermore, since orthophosphate was present in all solutions, the precipitation of hydroxyapatite $\left(\mathrm{Ca}_{5}\left(\mathrm{PO}_{4}\right)_{3} \mathrm{OH}\right)$ was likely at $\mathrm{pH}>8$ (calculations performed in PHREEQC). Therefore, the enhanced elimination for the solutions $\mathrm{I}, \mathrm{K}$, and $\mathrm{L}$ at $\mathrm{pH}>8 \mathrm{can}$ be ascribed to the precipitation of 
hydroxyapatite and/or Ca-DTPMP complexes. Both of these precipitates would lead to an elimination of organic phosphorus, either by direct precipitation (Ca-DTPMP complexes) or adsorption on the precipitate (hydroxyapatite) [48]. In the absence of calcium but with magnesium present (solution $\mathrm{J})$, the observed precipitation was shifted towards the more alkaline $\mathrm{pH}$ range $(\mathrm{pH}>10)$, which is consistent with the observation that in the presence of GFH at $\mathrm{pH}>10$ an increased removal occurred. Calculations performed with PHREEQC predict precipitation of $\mathrm{Mg}(\mathrm{OH})_{2}$, which is a known adsorbent for phosphorus compounds [49], from pH 10 onwards.

With additional (hydrogen-)carbonate ions (solutions $\mathrm{M}$ and $\mathrm{N}$ ), a stronger removal and, thus, a stronger precipitation occurred, compared with the previously discussed solutions (without GFH, see Figures $4 \mathrm{~d}$ and $5 \mathrm{~d}$ ). Calculations performed with PHREEQC, without taking DTPMP into account, showed that the solubility limit of $\mathrm{CaCO}_{3}$, dolomite $\left(\mathrm{CaMg}\left(\mathrm{CO}_{3}\right)_{2}\right)$, and hydroxyapatite was exceeded in solutions $\mathrm{M}$ and $\mathrm{N}$ from $\mathrm{pH} 7$ onwards. Since no precipitation occurred at $\mathrm{pH} 7$, this precipitation must have been impeded by the phosphonate. Above $\mathrm{pH} \mathrm{8}$, however, these three compounds could be precipitated and all of them, as possible adsorbents, could have led to the removal of phosphorus [16,48,50-52]. In keeping with the enhanced precipitation observed at $\mathrm{pH}>8$, elimination also increased in the batches with GFH at higher $\mathrm{pH}$ values (Figures $4 \mathrm{c}$ and $5 \mathrm{c}$ ).

The behavior of solution $\mathrm{N}$, the near-complete synthetic replica of the membrane concentrate, and the real membrane concentrate were very similar. Therefore, it can be concluded that all ions that strongly influence phosphonate adsorption were considered in the replica. In conclusion, the competing effect of anions present in the membrane concentrate on phosphonate adsorption can be ranked as follows: $\mathrm{HCO}_{3}{ }^{-}>>\mathrm{SO}_{4}{ }^{2-}, \mathrm{NO}_{3}{ }^{-}$. Particularly at $\mathrm{pH}$ values $>8, \mathrm{Ca}{ }^{\mathrm{II}}$ has a positive effect on phosphorus removal, mainly due to precipitation. The same applies to $\mathrm{MgII}^{\mathrm{II}}$ at $\mathrm{pH}$ values $>10$. The influence of the investigated ions on adsorption of DTPMP and $\mathrm{PO}_{4}-\mathrm{P}$ is nearly identical.

\section{Conclusions}

The influence of different compounds in membrane concentrate on the adsorption of phosphonates and phosphate on GFH was investigated. Of all phosphonates tested, HEDP was the phosphonate with the lowest calcium tolerance (precipitation already at a molar Ca:HEDP ratio of 2:1 after seven days contact time). The calcium already contained in the GFH plays an essential role in the elimination process, as it can be re-dissolved, causing a positive effect on the elimination of phosphonates. A further increase in $\mathrm{Ca}^{\mathrm{II}}$ concentration also caused precipitation of the phosphonates NTMP and DTPMP at $\mathrm{pH}$ values $>8$, likely as Ca-phosphonate complexes. NTMP and DTPMP showed a similar adsorption behavior, but the solubility of Ca-NTMP complexes was lower than that of Ca-DTPMP complexes. Experiments with membrane concentrate and its synthetic replicas showed that $\mathrm{HCO}_{3}{ }^{-}$has a competing effect on phosphorus adsorption, whereas the influence of $\mathrm{SO}_{4}{ }^{2-}$ and $\mathrm{NO}_{3}{ }^{-}$is negligible. $\mathrm{Up}$ to $\mathrm{pH}$ 8, the presence of $\mathrm{Ca}^{\mathrm{II}}$ has a positive effect on adsorption, probably due to the formation of ternary complexes. The presence of $\mathrm{Ca}^{\mathrm{II}}(\mathrm{at} \mathrm{pH}>8)$ and $\mathrm{Mg}^{\mathrm{II}}($ at $\mathrm{pH}>10)$ led to the formation of precipitates that served as adsorbents for phosphorus compounds, either through direct precipitation of Ca-phosphonate complexes, or through the formation of inorganic precipitates of calcium, magnesium, and phosphate. An additional presence of (hydrogen-)carbonate ions resulted in precipitation of $\mathrm{CaCO}_{3}$ and/or dolomite, which also acted as adsorbents for phosphorus compounds. The influence of the investigated ions on the adsorption of DTPMP and $\mathrm{PO}_{4}-\mathrm{P}$ is nearly identical. It can be assumed that membrane concentrate with its high content of $\mathrm{Ca}^{2+}$ and $\mathrm{Mg}^{2+}$ is well suited for treatment with GFH. Since $\mathrm{Ca}^{\mathrm{II}}$ is re-dissolved from GFH, future experiments should examine whether sufficient phosphonate is still removed after multiple use. In addition, it is important to investigate whether the precipitates interfere with the adsorption or regeneration process.

Supplementary Materials: The following are available online, Table S1: Removal of NTMP by precipitation at different calcium concentrations and $\mathrm{pH}$ values with standard deviations, Table S2: Removal of DTPMP by precipitation at different calcium concentrations and $\mathrm{pH}$ values with standard deviations. 
Author Contributions: Conceptualization, T.R. and E.R.; Funding acquisition, R.M. and E.R.; Investigation, T.R. and A.N.V.C.; Methodology, T.R. and E.R.; Project administration, R.M. and E.R.; Resources, H.S.; Supervision, T.R. and E.R.; Visualization, T.R.; Writing-original draft, T.R.; Writing-review \& editing, T.R. and E.R. All authors have read and agreed to the published version of the manuscript.

Funding: We would like to acknowledge our gratitude to the Willy-Hager-Stiftung, Stuttgart, for their financial support.

Acknowledgments: We would like to thank HeGo Biotec $\mathrm{GmbH}$ for providing adsorbent samples, and Zschimmer \& Schwarz Mohsdorf GmbH \& Co. KG for supplying us with phosphonate samples.

Conflicts of Interest: The authors declare no conflict of interest.

\section{References}

1. European Phosphonate Association (EPA). Phosphonates in Detergents: EPA Detergent Phosphonates Dossier; EPA: Brussels, Belgium, 2013.

2. Davenport, B.; DeBoo, A.; Dubois, F.; Kishi, A. CEH Report: Chelating Agents; SRI Consulting: Menlo Park, CA, USA, 2000.

3. Nowack, B.; Stone, A.T. Adsorption of Phosphonates onto the Goethite-Water Interface. J. Colloid Interface Sci. 1999, 214, 20-30. [CrossRef] [PubMed]

4. Boels, L.; Keesman, K.J.; Witkamp, G.-J. Adsorption of phosphonate antiscalant from reverse osmosis membrane concentrate onto granular ferric hydroxide. Environ. Sci. Technol. 2012, 46, 9638-9645. [CrossRef] [PubMed]

5. Armbruster, D.; Müller, U.; Happel, O. Characterization of phosphonate-based antiscalants used in drinking water treatment plants by anion-exchange chromatography coupled to electrospray ionization time-of-flight mass spectrometry and inductively coupled plasma mass spectrometry. J. Chromatogr. A 2019, 1601, 189-204. [CrossRef] [PubMed]

6. Squire, D. Reverse osmosis concentrate disposal in the UK. Desalination 2000, 132, 47-54. [CrossRef]

7. Nederlof, M.M.; Hoogendoorn, J.H. Desalination of brackish groundwater: The concentrate dilemma. Desalination 2005, 182, 441-447. [CrossRef]

8. Greenlee, L.F.; Lawler, D.F.; Freeman, B.D.; Marrot, B.; Moulin, P. Reverse osmosis desalination: Water sources, technology, and today's challenges. Water Res. 2009, 43, 2317-2348. [CrossRef]

9. Rott, E.; Happel, O.; Armbruster, D.; Minke, R. Influence of Wastewater Discharge on the Occurrence of PBTC, HEDP, and Aminophosphonates in Sediment, Suspended Matter, and the Aqueous Phase of Rivers. Water 2020, 12, 803. [CrossRef]

10. Kuhn, R.; Jensch, R.; Bryant, I.M.; Fischer, T.; Liebsch, S.; Martienssen, M. The influence of selected bivalent metal ions on the photolysis of diethylenetriamine penta (methylenephosphonic acid). Chemosphere 2018, 210, 726-733. [CrossRef]

11. Lesueur, C.; Pfeffer, M.; Fuerhacker, M. Photodegradation of phosphonates in water. Chemosphere 2005, 59, 685-691. [CrossRef]

12. Nowack, B. Environmental chemistry of phosphonates. Water Res. 2003, 37, 2533-2546. [CrossRef]

13. Tang, Y.; Yang, W.; Yin, X.; Liu, Y.; Yin, P.; Wang, J. Investigation of $\mathrm{CaCO}_{3}$ scale inhibition by PAA, ATMP and PAPEMP. Desalination 2008, 228, 55-60. [CrossRef]

14. Jonasson, R.G.; Rispler, K.; Wiwchar, B.; Gunter, W.D. Effect of phosphonate inhibitors on calcite nucleation kinetics as a function of temperature using light scattering in an autoclave. Chem. Geol. 1996, 132, 215-225. [CrossRef]

15. Yang, Q.; Liu, Y.; Gu, A.; Ding, J.; Shen, Z. Investigation of Calcium Carbonate Scaling Inhibition and Scale Morphology by AFM. J. Colloid Interface Sci. 2001, 240, 608-621. [CrossRef]

16. Kan, A.T.; Fu, G.; Tomson, M.B. Adsorption and precipitation of an aminoalkylphosphonate onto calcite. J. Colloid Interface Sci. 2005, 281, 275-284. [CrossRef]

17. Chen, Y.; Baygents, J.C.; Farrell, J. Removing phosphonate antiscalants from membrane concentrate solutions using granular ferric hydroxide. J. Water Process Eng. 2017, 19, 18-25. [CrossRef]

18. Reinhardt, T.; Elordi, M.G.; Minke, R.; Schönberger, H.; Rott, E. Batch studies of phosphonate adsorption on granular ferric hydroxides. Water Sci. Technol. 2020, 81, 10-20. [CrossRef] [PubMed] 
19. Martínez, R.J.; Farrell, J. Understanding Nitrilotris (methylenephosphonic acid) reactions with ferric hydroxide. Chemosphere 2017, 175, 490-496. [CrossRef]

20. Stone, A.T.; Knight, M.A.; Nowack, B. Speciation and Chemical Reactions of Phosphonate Chelating Agents in Aqueous Media. In Chemicals in the Environment: Fate, Impacts, and Remediation, American Chemical Society; Lipnick, R.L., Ed.; Oxford University Press: Washington, DC, USA, 2002; pp. 59-94. [CrossRef]

21. Nowack, B.; Stone, A.T. The Influence of Metal Ions on the Adsorption of Phosphonates onto Goethite. Environ. Sci. Technol. 1999, 33, 3627-3633. [CrossRef]

22. Rott, E.; Reinhardt, T.; Wasielewski, S.; Raith-Bausch, E.; Minke, R. Optimized Procedure for Determining the Adsorption of Phosphonates onto Granular Ferric Hydroxide using a Miniaturized Phosphorus Determination Method. J. Vis. Exp. 2018, 135. [CrossRef]

23. Worch, E. Adsorption Technology in Water Treatment: Fundamentals, Processes, and Modeling; De Gruyter: Berlin, Germany, 2012.

24. Rott, E.; Happel, O.; Armbruster, D.; Minke, R. Behavior of PBTC, HEDP, and Aminophosphonates in the Process of Wastewater Treatment. Water 2020, 12, 53. [CrossRef]

25. ISO 6878. DIN EN ISO 6878:2004-09: Water Quality-Determination of Phosphorus-Ammonium Molybdate Spectrometric Method; Beuth Verlag GmbH: Berlin, Germany, 2004. [CrossRef]

26. DIN 38406-3. German Standard Methods for the Examination of Water, Waste Water and Sludge-Cations (Group E)_Part 3: Determination of Calcium and Magnesium, Complexometric Method (E 3); Beuth Verlag GmbH: Berlin, Germany, 2003. [CrossRef]

27. Rott, E.; Nouri, M.; Meyer, C.; Minke, R.; Schneider, M.; Mandel, K.; Drenkova-Tuhtan, A. Removal of phosphonates from synthetic and industrial wastewater with reusable magnetic adsorbent particles. Water Res. 2018, 145, 608-617. [CrossRef]

28. Garcia, C.; Courbin, G.; Ropital, F.; Fiaud, C. Study of the scale inhibition by HEDP in a channel flow cell using a quartz crystal microbalance. Electrochim. Acta 2001, 46, 973-985. [CrossRef]

29. Browning, F.H.; Fogler, H.S. Effect of Precipitating Conditions on the Formation of Calcium-HEDP Precipitates. Langmuir 1996, 12, 5231-5238. [CrossRef]

30. Pairat, R.; Sumeath, C.; Browning, F.H.; Fogler, H.S. Precipitation and Dissolution of Calcium-ATMP Precipitates for the Inhibition of Scale Formation in Porous Media. Langmuir 1997, 13, 1791-1798. [CrossRef]

31. Kan, A.T.; Oddo, J.E.; Tomson, M.B. Formation of Two Calcium Diethylenetriaminepentakis (methylene phosphonic acid) Precipitates and Their Physical Chemical Properties. Langmuir 1994, 10, 1450-1455. [CrossRef]

32. Zhang, B.; Zhang, L.; Li, F.; Hu, W.; Hannam, P.M. Testing the formation of Ca-phosphonate precipitates and evaluating the anionic polymers as $\mathrm{Ca}$-phosphonate precipitates and $\mathrm{CaCO}_{3}$ scale inhibitor in simulated cooling water. Corros. Sci. 2010, 52, 3883-3890. [CrossRef]

33. Amjad, Z.; Zuhl, R.W.; Zibrida, J.F. Factors Influencing the Precipitation of Calcium-Inhibitor Salts in Industrial Water Systems. In Proceedings of the Annual Convention, Association of Water Technologies, Phoenix, AZ, USA, 17 September 2003.

34. Popov, K.; Rönkkömäki, H.; Lajunen, L.H.J. Critical evaluation of stability constants of phosphonic acids (IUPAC Technical Report). Pure Appl. Chem. 2002, 74. [CrossRef]

35. Nowack, B.; Stone, A.T. Competitive adsorption of phosphate and phosphonates onto goethite. Water Res. 2006, 40, 2201-2209. [CrossRef] [PubMed]

36. Gledhill, W.E.; Feijtel, T.C.J. Environmental Properties and Safety Assessment of Organic Phosphonates Used for Detergent and Water Treatment Applications. In Detergents; de Oude, N.T., Ed.; Springer: Berlin/Heidelberg, Germany, 1992; pp. 261-285. [CrossRef]

37. Yan, F.; Zhang, F.; Bhandari, N.; Wang, L.; Dai, Z.; Zhang, Z.; Liu, Y.; Ruan, G.; Kan, A.; Tomson, M. Adsorption and precipitation of scale inhibitors on shale formations. J. Pet. Sci. Eng. 2015, 136, 32-40. [CrossRef]

38. Rahimi, T.; Vaezi, N.; Khazaei, M.; Vakili, B.; Izanloo, H. Application of Granular Ferric Hydroxide in Removal of Nitrate from Aqueous Solutions. J. Saf. Environ. Health Res. 2016, 1, 31-35. [CrossRef]

39. Zelmanov, G.; Semiat, R. The influence of competitive inorganic ions on phosphate removal from water by adsorption on iron $\left(\mathrm{Fe}^{+3}\right)$ oxide/hydroxide nanoparticles-based agglomerates. J. Water Process Eng. 2015, 5, 143-152. [CrossRef] 
40. Boels, L.; Tervahauta, T.; Witkamp, G.J. Adsorptive removal of nitrilotris(methylenephosphonic acid) antiscalant from membrane concentrates by iron-coated waste filtration sand. J. Hazard. Mater. 2010, 182, 855-862. [CrossRef]

41. Geelhoed, J.S.; Hiemstra, T.; van Riemsdijk, W.H. Phosphate and sulfate adsorption on goethite: Single anion and competitive adsorption. Geochim. Cosmochim. Acta 1997, 61, 2389-2396. [CrossRef]

42. Violante, A.; Pigna, M.; Ricciardella, M.; Gianfreda, L. Adsorption of phosphate on variable charge minerals and soils as affected by organic and inorganic ligands. In Soil Mineral-Organic Matter-Microorganism Interactions and Ecosystem Health, Dynamics, Mobility and Transformation of Pollutants and Nutrients; Elsevier: Amsterdam, The Netherlands, 2002; pp. 279-295. [CrossRef]

43. Genz, A.; Kornmuller, A.; Jekel, M. Advanced phosphorus removal from membrane filtrates by adsorption on activated aluminium oxide and granulated ferric hydroxide. Water Res. 2004, 38, 3523-3530. [CrossRef]

44. Su, C.; Suarez, D.L. In Situ Infrared Speciation of Adsorbed Carbonate on Aluminum and Iron Oxides. Clays Clay Miner. 1997, 45, 814-825. [CrossRef]

45. Chitrakar, R.; Tezuka, S.; Sonoda, A.; Sakane, K.; Ooi, K.; Hirotsu, T. Phosphate adsorption on synthetic goethite and akaganeite. J. Colloid Interface Sci. 2006, 298, 602-608. [CrossRef]

46. Mendez, J.C.; Hiemstra, T. Carbonate Adsorption to Ferrihydrite: Competitive Interaction with Phosphate for Use in Soil Systems. ACS Earth Space Chem. 2019, 3, 129-141. [CrossRef]

47. Lin, J.; Zhao, Y.; Zhan, Y.; Wang, Y. Influence of coexisting calcium and magnesium ions on phosphate adsorption onto hydrous iron oxide. Environ. Sci. Pollut. Res. Int. 2020, 27, 11303-11319. [CrossRef]

48. Bartels, T.; Schuthof, J.; Arends, J. The adsorption of two polyphosphonates on hydroxyapatite and their influence on the acid solubility of whole bovine enamel. J. Dent. 1979, 7, 221-229. [CrossRef]

49. Lin, J.; He, S.; Wang, X.; Zhang, H.; Zhan, Y. Removal of phosphate from aqueous solution by a novel $\mathrm{Mg}(\mathrm{OH})_{2} / \mathrm{ZrO}_{2}$ composite: Adsorption behavior and mechanism. Colloids Surf. A Physicochem. Eng. Asp. 2019, 561, 301-314. [CrossRef]

50. Chirby, D.; Franck, S.; Troutner, D.E. Adsorption of 153Sm-EDTMP on calcium hydroxyapatite. Int. J. Radiat. Appl. Instrum. Part A Appl. Radiat. Isot. 1988, 39, 495-499. [CrossRef]

51. Xu, N.; Chen, M.; Zhou, K.; Wang, Y.; Yin, H.; Chen, Z. Retention of phosphorus on calcite and dolomite: Speciation and modeling. RSC Adv. 2014, 4, 35205. [CrossRef]

52. Karaca, S.; Gürses, A.; Ejder, M.; Açikyildiz, M. Adsorptive removal of phosphate from aqueous solutions using raw and calcinated dolomite. J. Hazard. Mater. 2006, 128, 273-279. [CrossRef]

Sample Availability: Samples of the compounds are not available.

Publisher's Note: MDPI stays neutral with regard to jurisdictional claims in published maps and institutional affiliations.

(C) 2020 by the authors. Licensee MDPI, Basel, Switzerland. This article is an open access article distributed under the terms and conditions of the Creative Commons Attribution (CC BY) license (http://creativecommons.org/licenses/by/4.0/). 